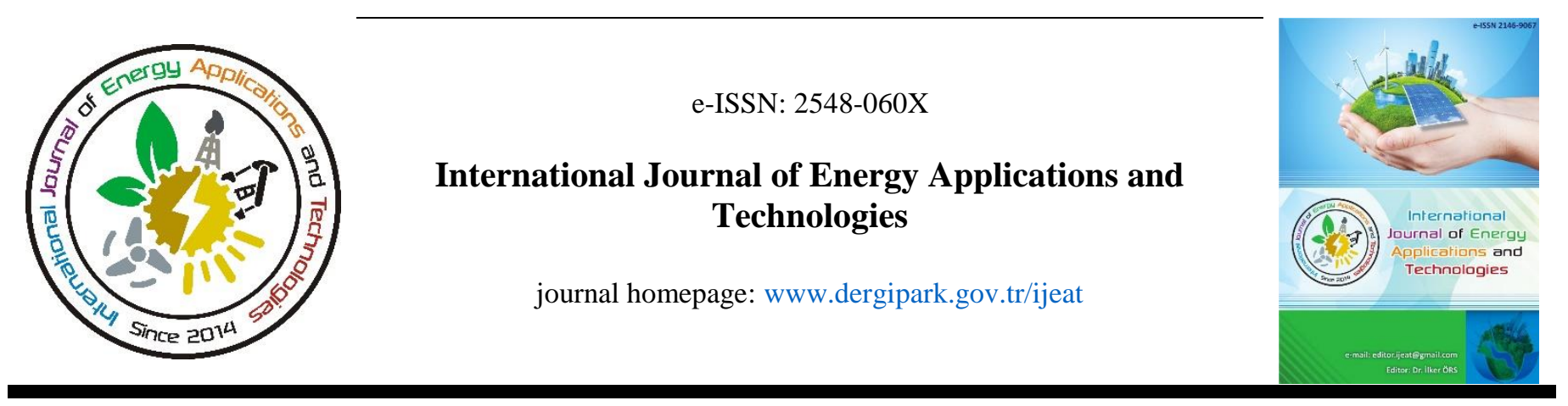

Original Research Article

\title{
Biodiesel production using reactive distillation column: Real time model predictive control in Matlab Simulink
}

\author{
Süleyman Karacan \\ Ankara University, Engineering Faculty, Department of Chemical Engineering, Tandoğan 06100, Ankara, Turkey
}

\author{
ARTICLE INFO \\ * Corresponding author \\ karacan@eng.ankara.edu.tr \\ Received June 28, 2018 \\ Accepted October 15, 2018 \\ Published by Editorial Board \\ Members of IJEAT \\ (C) This article is distributed by \\ Turk Journal Park System under \\ the CC 4.0 terms and conditions \\ doi:10.31593/ijeat.437998
}

\begin{abstract}
Biodiesel is a renewable fuel source that consist of alkyl esters obtained from vegetable oil and animal fats. Biodiesel is typically produced via transesterification, which is the reaction of vegetable oils with a short-chain alcohol to produce alkyl esters and glycerol by using an appropriate catalyst. Reactive distillation is integrated operations that conveniently combine reaction and separation into a single unit. It is an effective alternative to the traditional combination of reactor and separation units especially when involving in reversible reactions, such as vegetable oil transesterification, or consecutive chemical reactions. Biodiesel production process by reactive distillation is a high degree nonlinear structure and multi-input and multioutput system. Because of this state, reactive distillation systems should be controlled. In this study, reboiler heat duty used as a manipulated variable to control the temperature of the bottom product. Model Predictive Control (MPC) was carried out and control results was satisfactorily obtained.
\end{abstract}

\section{Introduction}

Reactive distillation (RD) is a chemical unit operation in which chemical reactions and separations occur simultaneously in one unit. It is an effective alternative to the traditional combination of reactor and separation units especially when involving in reversible reactions, such as vegetable oil transesterification, or consecutive chemical reactions. The significant advantages of the RD over the conventional sequential process are the high chemical conversion rate and low capital and operational cost. The performance of a reactive distillation column is influenced by several parameters, e.g. operating temperatures, size of reactive and separation zones, reflux ratio, feed rate and location, etc, which were thoroughly investigated. In addition to the advantages mentioned before, basically, the combination of reaction and distillation in the same equipment unit gives rise to suppression of side reaction(s) and utilization of heat evolved from an exothermic reaction for mass transfer operation. These synergistic effects of the process result in low energy cost and high product yields [1, 2]. However, as a result of combining reaction and separation in a single piece of equipment in this process, its control has been a challenge to process engineers because it must be handled using a robust control method that will be able to take care of the complexities involved in it. This is the reason why the application of model predictive control (MPC) to it is being investigated further. Model predictive control is an advanced control technique that is used for difficult control problems [3, 4], and it has its primary advantage to be the explicit handling of constraints [3,5]. MPC is an appropriately descriptive name for computer control schemes that utilize a process model for two explicit prediction of future behavior and computation of appropriate corrective control action required to drive the predicted output as close 
as possible to the desired target value in an optimal manner. As an advanced control method, MPC has enjoyed such remarkable industrial

success and popularity that, currently, it is the most widely utilized of all advanced control methodologies in industrial applications [3, 6-8].

Biodiesel, as an alternative fuel, has many merits. It is derived from a renewable, domestic resource, thereby relieving reliance on petroleum fuel imports. It is biodegradable and non-toxic. Compared to petroleum-based diesel, biodiesel has a more favorable combustion emission profile, such as low emissions of carbon monoxide, particulate matter and unburned hydrocarbons. Carbon dioxide produced by combustion of biodiesel can be recycled by photosynthesis, thereby minimizing, the impact of biodiesel combustion on the greenhouse effect $[9,10]$. Base catalysts include homogeneous base catalysts and heterogeneous base catalysts.

The commonly used homogeneous catalysts are $\mathrm{NaOH}, \mathrm{KOH}$ and their alkoxides. Homogeneous alkali-catalyzed transesterification is much faster than acid-catalyzed transesterification [11]. However, a large amount of water is required to transfer the catalysts from the organic phase to a water phase after the reaction. Therefore, it is considerably more costly to separate the catalyst from the produced solution [11, 12]. Heterogeneous base catalysts have many advantages: they are noncorrosive, environmentally benign and present fewer disposal problems. Meanwhile, they are much more easily separated from the liquid products and can be designed to give higher activity, selectivity and longer catalyst lifetimes [13]. Many researchers have studied calcium oxide $(\mathrm{CaO})$ as a strong candidate for the heterogeneous catalyst, due to the commercial availability, the economical advantage and the relatively higher activity [14, 15]. Heterogeneous catalytic transesterification reactions required higher methanol-to-oil molar ratio to forward the reaction toward product side which leads to increase the production cost of biodiesel. In order to reduce the methanol-to-oil ratio, an ideal system for continuous production of biodiesel is the application of reactive distillation technique. In the reactive distillation system, the excess/ unreacted methanol was completely vaporized by the reboiler and the vapors were recirculated in the RD column and utilized in the reactive zone. Hence, the methanol-to-oil ratio is reduced significantly [16]. Transesterification of palm oil with methanol in the presence of potassium hydroxide as homogeneous catalyst in reactive distillation column was studied by Prasertsit, Mueanmas, and Tongurai (2013). A maximum methyl ester conversion of $92.27 \%$ was reported under the optimal conditions of reboiler temperature at $90^{\circ} \mathrm{C}$, methanol- to-oil ratio at 4.5:1 and $\mathrm{KOH}$ at $1 \mathrm{wt} \%$. Agarwal et al. [17] studied continuous transesterification of karanja oil in the reactive distillation (RD) system and helical tube system using $\mathrm{KOH}$ as homogeneous catalyst. Therefore, a heterogeneous catalyst operated RD system is needed to check the feasibility of continuous production of biodiesel.

Niju et al. [18] investigated continuous flow transesterification of waste frying oil (WFO) with methanol for the biodiesel production in a laboratory scale jacketed reactive distillation unit packed with clam shell based $\mathrm{CaO}$ as solid catalyst. The effects of operating parameters on methyl ester conversion were investigated and discussed. Oguz and Celik Tolu [19] published a review for optimization anal Reactive distillation, Biodiesel, Simulation, MPC ysis of biodiesel production from vegetable oil by using bio $\mathrm{CaO}$ as Catalyst. $\mathrm{CaO}$ catalyst which is synthesized by calcination of egg shells is used to evaluate waste shells and increase the quality of reaction [20].

In this work, the $\mathrm{RD}$ system packed with $\mathrm{CaO}$ was studied for the biodiesel production to develop a continuous heterogeneous catalyzed process. The effects of operating parameters on methyl ester conversion were investigated and to carry out the control of the process for set-point tracking by applying model predictive control.

\section{Material and Methods}

Sunflower oil and methanol were used as a feedstock for the biodiesel production. Heterogenous basic $\mathrm{CaO}$ catalyst was used for the biodiesel production. Sunflower oil was supplied from an oil production plant. Methanol and $\mathrm{CaO}$ were purchased from Sigma-Aldrich. The process involved in this work was a transesterification reaction occurring simultaneously with distillation operation that were carried out in the reactive packed distillation column set up as shown pictorially in Fig. 1a and schematically in Fig. 1b. The column, excluding the condenser and the reboiler, had a height of $1.5 \mathrm{~m}$ and a diameter of $0.05 \mathrm{~m}$. It consisted of a cylindrical condenser with a diameter and a height of 5 and $22.5 \mathrm{~cm}$ respectively. The main column section of the plant was divided into two subsections. The upper and lower sections were the reaction and the stripping sections respectively. The stripping section was packed with raschig rings while the reaction section was filled with small lumps 3-20 mm of $\mathrm{CaO}$ solid. The reboiler was spherical in shape with a volume of 3 Liter. The column was fed with sunflower oil and Methanol at the top. All the signal inputs (reflux ratio $(\mathrm{R})$, feed ratio $(\mathrm{F})$ and reboiler duty $(\mathrm{Q})$ to the column and the measured outputs (top segment temperature, reaction segment temperature and bottom segment temperature (TB)) from the column were sent and recorded respectively on-line with the aid of MATLAB/Simulink computer program and electronic input-output $(\mathrm{I} / \mathrm{O})$ modules that were connected to the equipment and the computer system. This block diagram was shown in Fig. 2. 


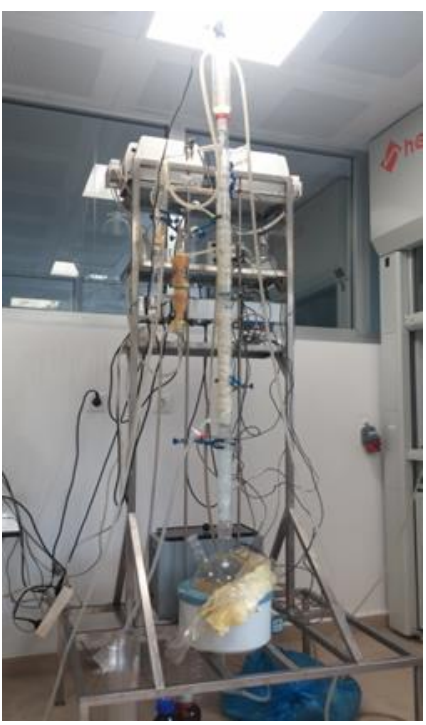

(a)

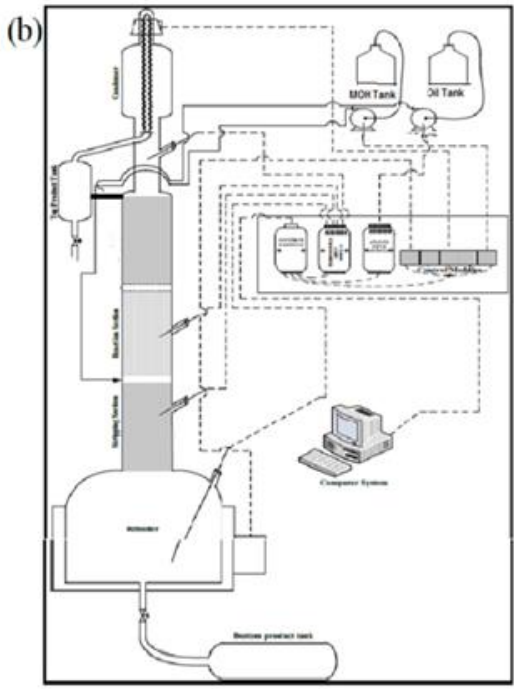

(b)

Figure 1. Reactive packed distillation column: (a) Pictorial view; (b) Sketch view

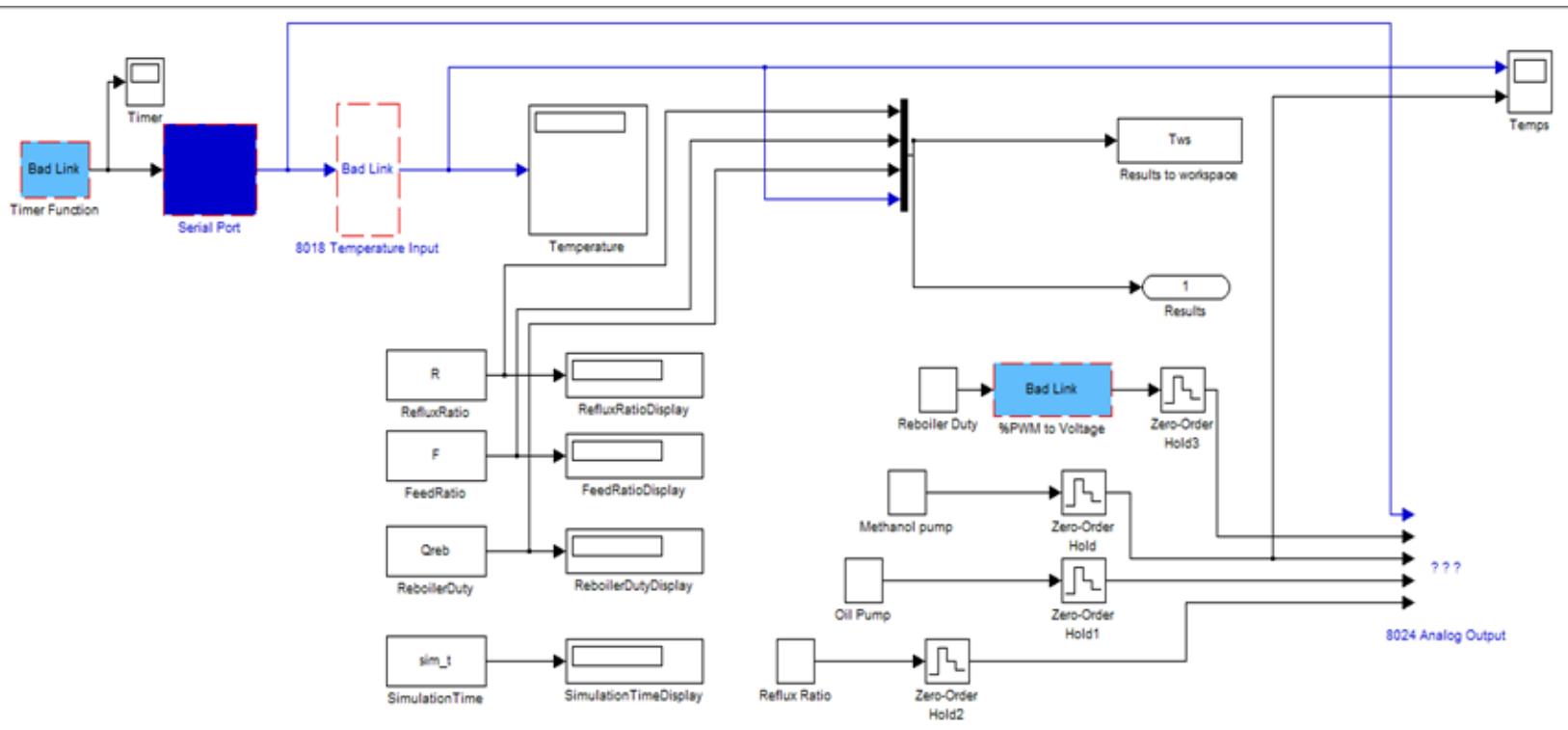

Figure 2. Block diagram in which experimental data are received and recorded

\subsection{Transesterification reaction}

Transesterification of vegetable oils with alcohol is the best method for biodiesel production. There are two transesterification methods, which are: (a) with catalyst and (b) without catalyst. The utilization of different types of catalysts improves the rate and yield of biodiesel. The transesterification reaction is reversible and excess alcohol shifts the equilibrium to the product side $[19,20]$. A generic transesterification reaction is presented in Eq (1); RCOOR' indicates an ester mixture and cat a catalyst:

\section{cat}

RCOOR'+ R'
When methanol is the alcohol used in the transesterification process, the product of the reaction is a mixture of methyl esters. glycerin will be the co-product of the reaction. This is shown schematically in Fig. 3. Many different alcohols can be used in this reaction, including, methanol, ethanol, propanol, and butanol. The methanol application is more feasible because of its low-cost and physical as well as chemical advantages, such as being polar and having the shortest alcohol chain [21]. According to Fig. 3, $\mathrm{R}_{1}, \mathrm{R}_{2}$, and $\mathrm{R}_{3}$ are long chains of hydrocarbons and carbon atoms called fatty acid chains. The reaction is based on one mole of triglyceride reacting with three moles of methanol to produce three moles methyl ester (biodiesel) and one mole glycerol. 
Generally, the transesterification reaction involves some critical parameters which significantly influence the final conversion and yield. The most important variables are: reaction temperature, free fatty acid content in the oil, water content in the oil, type of catalyst, amount of catalyst, reaction time, molar ratio of alcohol to oil, type or chemical stream of alcohol, use of co-solvent and mixing intensity.

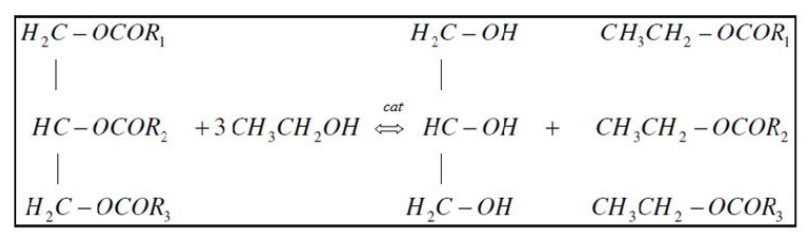

Figure 3. Basic transesterification reaction with methanol

\subsection{Transfer function modelling of the process}

The process model used in this work was formulated by adding the transfer function relation between the output variable (reboiler heat duty) and the disturbance variable developed using the data generated from the Fig. 1. The process model formulation was done with the aid of the
System Identification Toolbox contained in MATLAB [22]. The type of the transfer function model of the disturbance relation was also chosen to be the same as that of the main process transfer function, that is, first-order-plus-dead-time, and this made the model of the process to be as shown in Equation (2).

$$
T_{B}(s)=\frac{\left.K e^{(-t} d p^{s}\right)}{\tau_{p} s+1} Q(s)+\frac{K_{d} e^{(-t} d^{s)}}{\tau_{d} s+1} F(s)
$$

\subsection{Development of closed-loop Simulink models of the process}

The model predictive control of the reactive distillation process for the development of biodiesel (a renewable energy) was achieved by using the transfer function of the process obtained and given in Equation (1) to develop its Simulink models shown in Fig. 4 for servo (set-point tracking). The Simulink model was developed by picking and connecting appropriate blocks from the Simulink library of MATLAB [22].

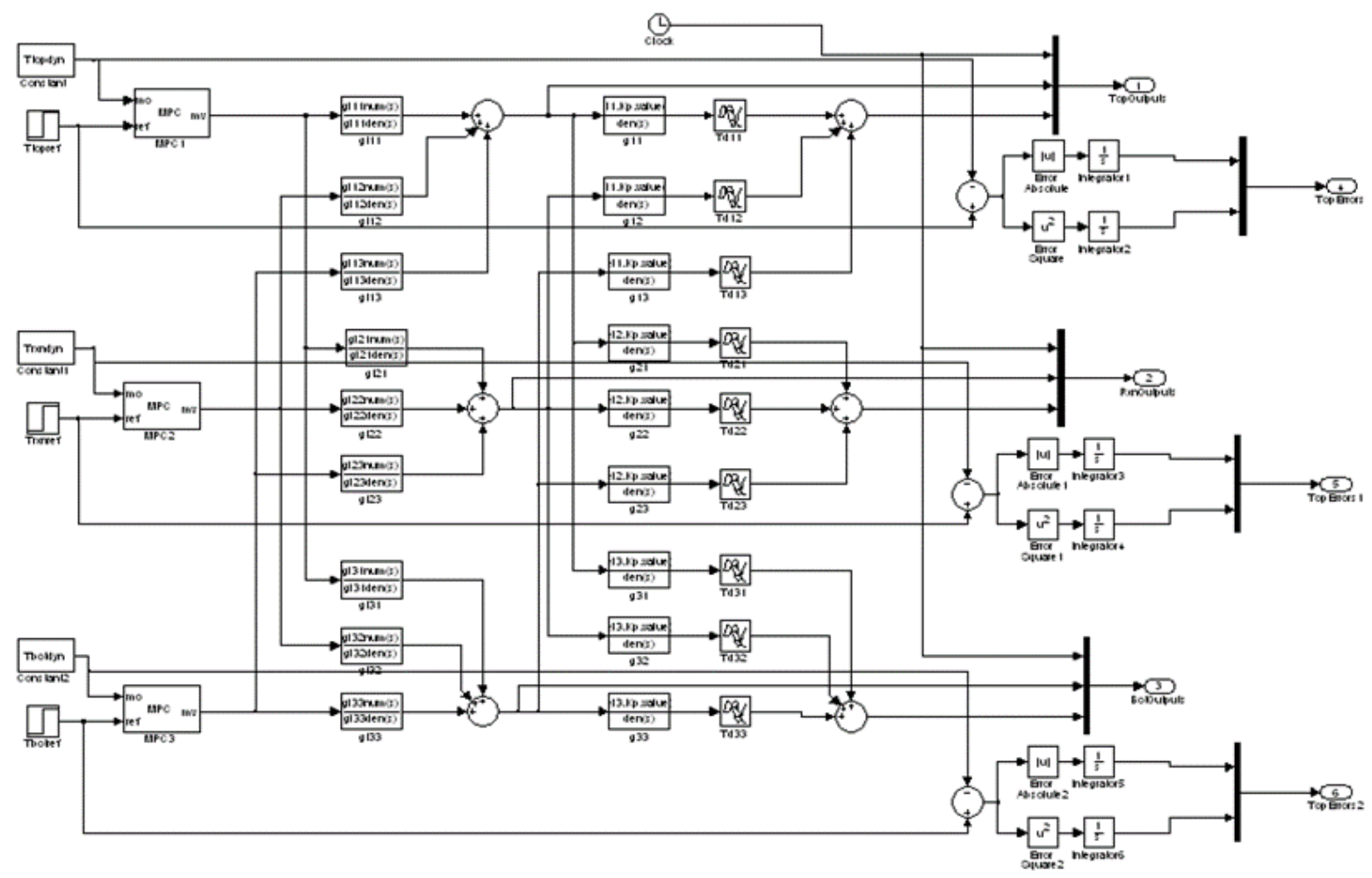

Figure 4. Simulink model of reactive distillation system for set-point tracking control

\section{Results and Discussion}

\subsection{Effect of reboiler heat duty on the biodiesel yield}

The reboiler of the system was heated using electrical heating element. Reaction conversion and separation occurred in the column. Apart from the biodiesel that was present in the reboiler, it was also discovered that there were some oil and methanol still present there too. The reason for the presence of these two components (oil and methanol) in the reboiler was due to the fact that oil, after being fed into the column at 
the oil feed section, was moving down the column towards the reboiler while methanol, being more volatile, was finding its way upwards and the two reactants were meeting at the reaction section where the reaction was taking place. The unreacted portions of these two reactants were definitely moving downwards to the reboiler and settling there before they were boiled to move up again as a mixed vapour. It was also discovered that the presence of oil and methanol in the reboiler gave rise to the occurrence of reaction there too. That is to say that the reboiler also served, to some extent, as a reactor in a reactive distillation process. Reboiler heat duty was important role in obtaining the product. The effect on the column temperatures was examined by applying a positive step to the reboiler heat duty to keep the other conditions the same. Step was changed from $490 \mathrm{~W}$ to $670 \mathrm{~W}$. The experimental data obtained were given in Figs. 5-7. As seen in the Figures, the positive effects on reboiler heat duty were increased in the temperatures of the reactive distillation column.

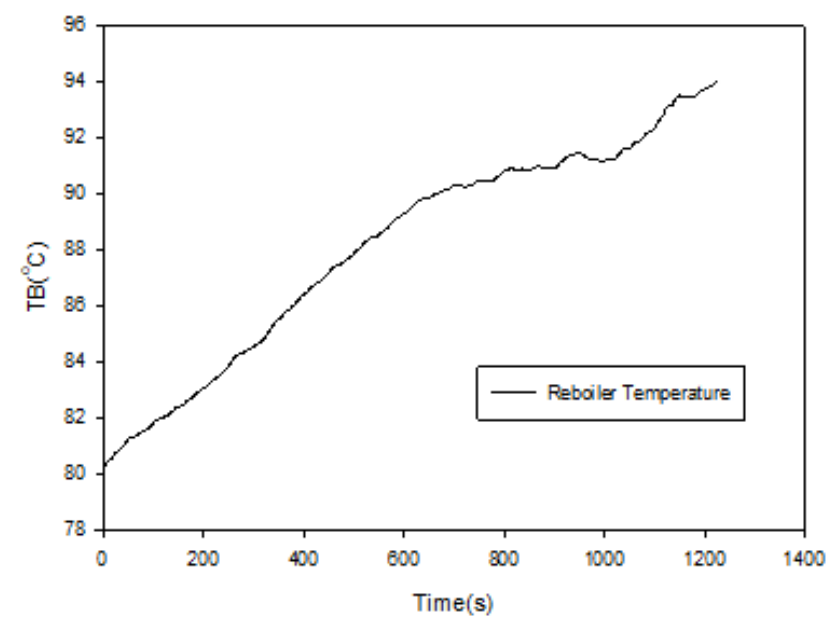

Figure 5. Effect of the reboiler heat duty on the reboiler temperature

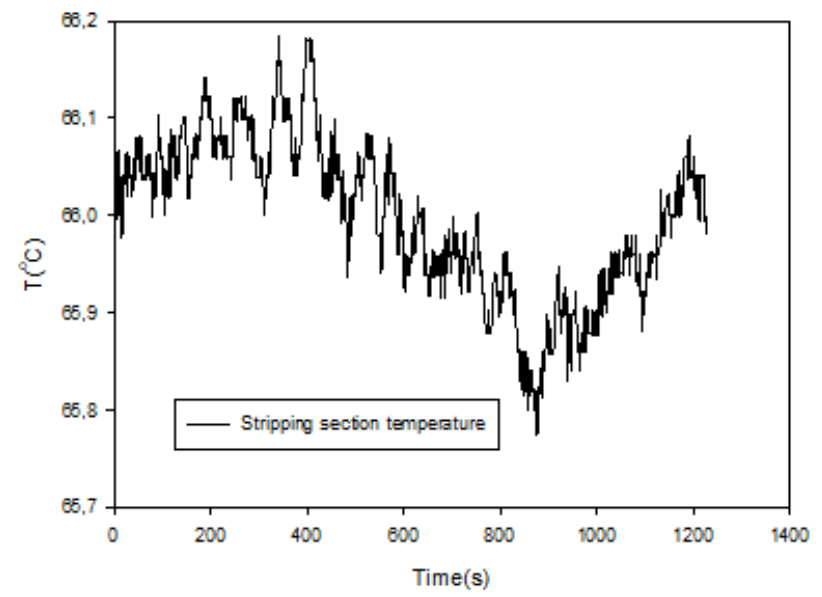

Figure 6. Effect of the reboiler duty on the stripping section temperature

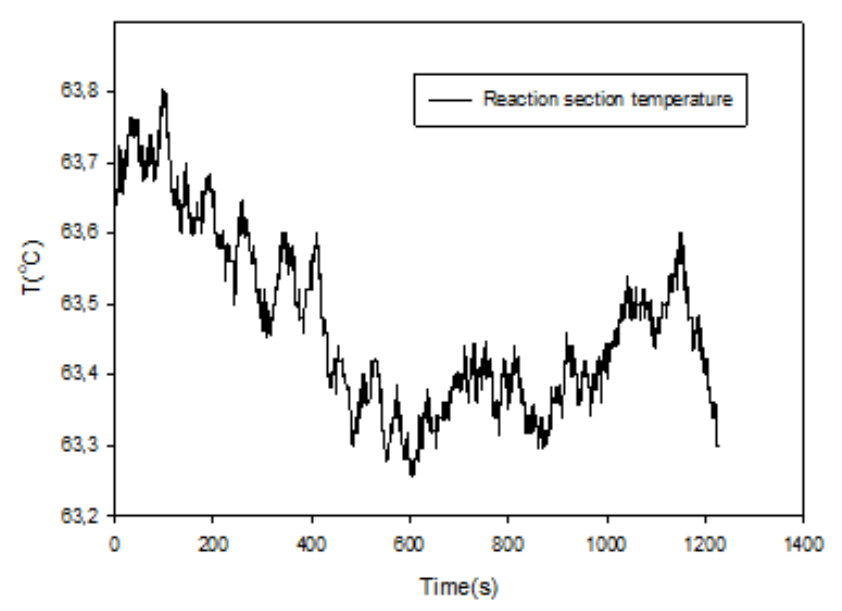

Figure 7. Effect of the reboiler duty on the reaction section temperature

\subsection{Effect of molar ratio of methanol to oil on biodiesel yield}

Steady-state and dynamic studies were carried out in the system. The effect alcohol-oil ratio on the system was investigated. The reactant flow rate is one of the most important parameters in continuous flow RD system. At very low feed flow rates, liquid film formed on the catalyst surface enhanced the mass transfer resistance and lowered the methyl ester conversion. However, an increase in the feed flowrate reduces the mass transfer limitation and results in higher methyl ester conversion. Experimental studies were carried out in a reactive distillation column given in Fig. 1. In order to see the effects of the feed flow rate ratio on the system, dynamic experimental studies were carried out by keeping the oil flow rate constant and positively affecting the methanol flow rate. In the steady state condition, the reboiler heat duty, Q value is $490 \mathrm{~W}$, feed flow rates of methanol and oil were $4 \mathrm{ml} / \mathrm{min}$ at a $6: 1 \mathrm{molar}$ ratio of methanol to oil and reflux ratio was selected as 3 . The reboiler temperature, the stripping zone temperature and the reaction zone temperatures were measured in the system. In order to bring the system into a dynamic state, firstly the flow rate of Methanol was increased from $4 \mathrm{ml} / \mathrm{min}$ to $5 \mathrm{ml} / \mathrm{min}$ for 600 second at a 8:1 molar ratio of methanol to oil. Later, the flow rate of Methanol was increased from $5 \mathrm{ml} / \mathrm{min}$ to $6 \mathrm{ml} / \mathrm{min}$ for 600 second and then increased from $6 \mathrm{ml} / \mathrm{min}$ to 7 $\mathrm{ml} / \mathrm{min}$ for 760 second at a 10:1 molar ratio of methanol to oil. The experimental data obtained were given in Figs. 8-10. As seen in the Figures, the positive effects on methanol flow rate were increased in the temperatures of the reactive distillation column.

The biodiesel yield could be improved by introducing excess amounts of methanol to shift the equilibrium to the righthand side. The experimental results, illustrated in Fig. 11, indicate the feed flow ratio of methanol to oil has a significant 
impact on the biodiesel yield. The biodiesel yields grew as the molar ratio increased, and the yield was $78.96 \%$ at a $6: 1$ molar ratio of methanol to oil when analytical reagent methanol was used. In comparison, the biodiesel yield increased from $74 \%$ to $93 \%$ when the molar ratio was increased from 4:1 to $10: 1$.

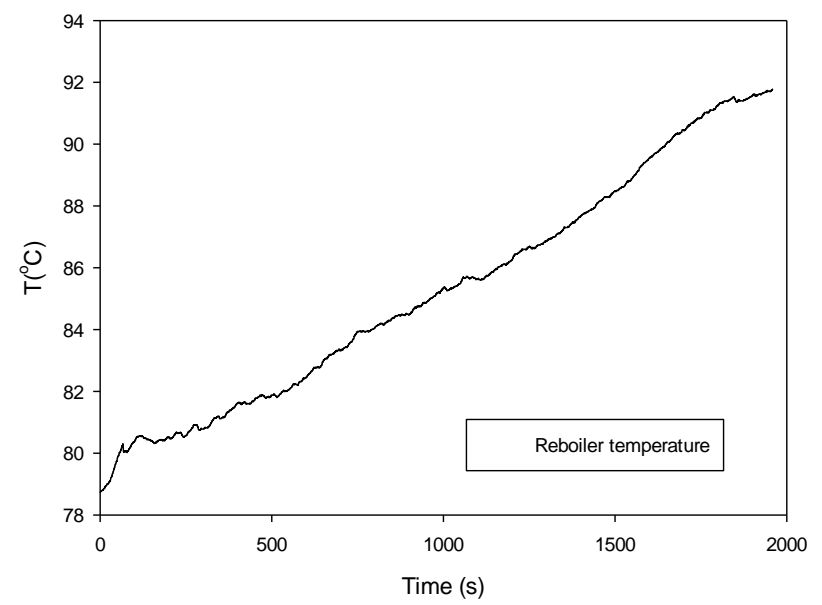

Figure 8. Effect of the flow rate of methanol on the reboiler temp.

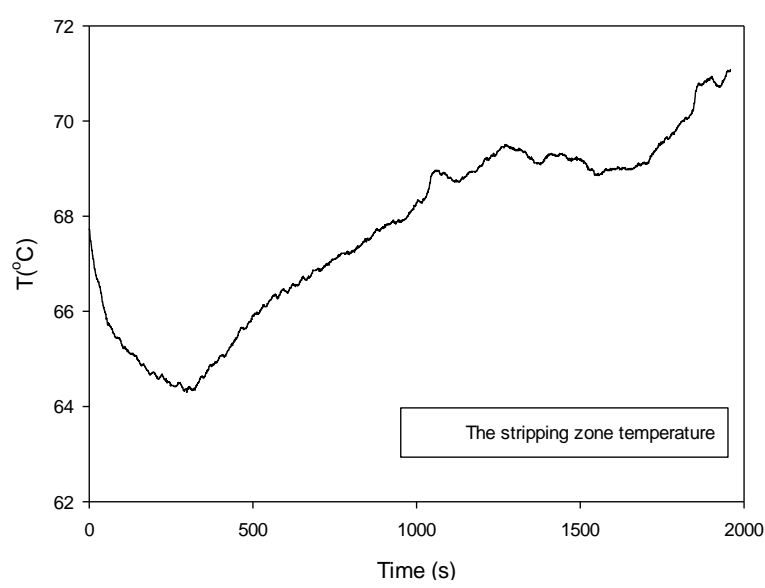

Figure 9.Effect of the flow rate of methanol on the stripping zone temp.

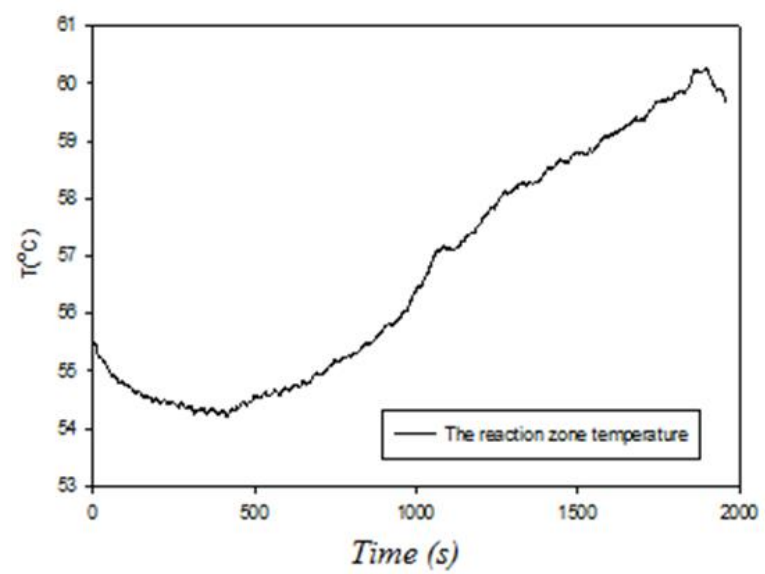

Figure 10.Effect of the flow rate of methanol on the reaction zone temp.

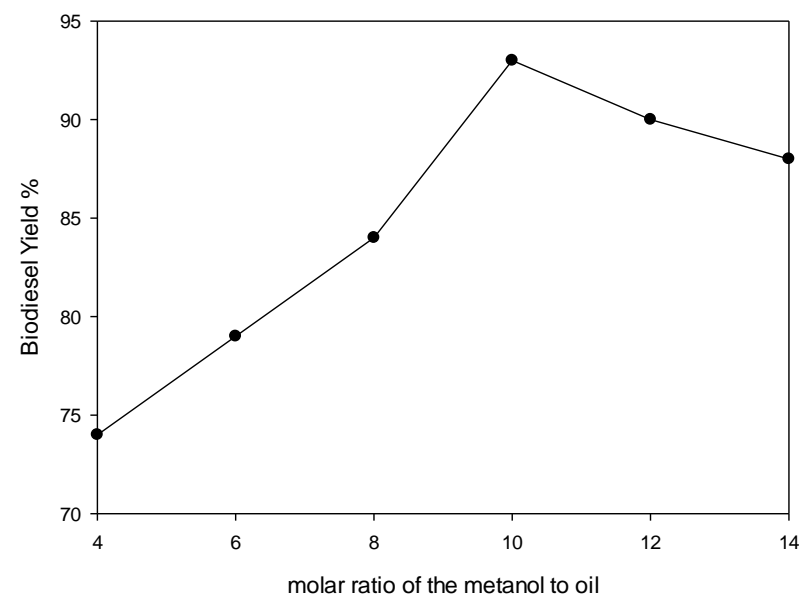

Figure 11. Effect of molar ratio of methanol to oil on biodiesel yield

However, the yields were slightly reduced when the ratio of methanol to oil was higher than 12:1, and the biodiesel yield was only $88 \%$ at $14: 1$. The reason is that the catalyst content decreased with increase of methanol content. Therefore, the optimum molar ratio of methanol to oil was 10:1.

\subsection{Model predictive control results}

The resulting model obtained for the process after the incorporation of the disturbance transfer function model term was as given in equation (3).

$T_{B}(s)=\frac{0.051 e^{(-1.59 s)}}{1.79 s+1} Q(s)+\frac{0.27 e^{(-24.13 s)}}{0.38 s+1} F(s)$

From Equation (3), it was observed that all the parameters (static gain, time constant and dead time) of the disturbance transfer model were, in magnitude, less than those of the main process transfer function model of the process. The lower time constant of the disturbance model was found to be an indication of the fact that the disturbance would respond faster than the main process if the same unit step change is applied to the two of them. In order to demonstrate the application of model predictive control to product biodiesel, the values of the optimum tuning parameters were set to control horizon as 8 , prediction horizon as 12 , Weight on manipulated variable rate as 0.05 and Weight on output variable as 2.25. Concentration control is not practically possible, this is because measurements can be done off-line and this is not good in terms of control performance as it causes considerable delays in the system. Therefore, temperature control was performed. In this study, the reboiler temperature of the system was controlled because to biodiesel was taken from the bottom product. To control the reboiler temperature, the $\mathrm{Q}$ heat given to the boiler as an adjustable variable was selected. In experimental studies, the system was controlled by computer. MPC control block 
diagram in Matlab Simulink was given in Fig.4. In addition, the block diagram in which the experimental data was taken and recorded on-line is also shown in Fig.2. the closed-loop control system of the reactive distillation column was controlled for set-point tracking by applying step changes to the value of the bottom section of the column, which was the controlled variable of the system, and the results obtained were as given in Fig. 12.
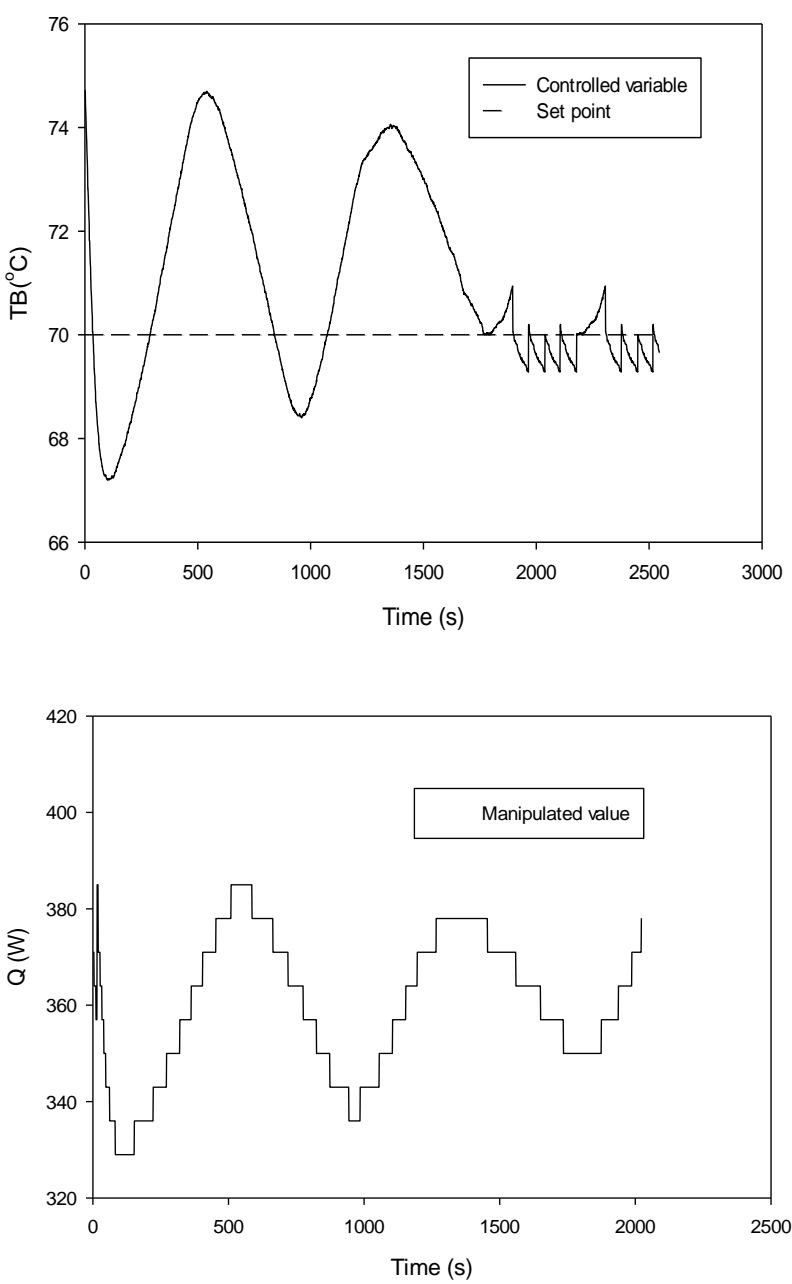

Figure 12. Shows the MPC results for set point of the reboiler temperature changes from $74.72^{\circ} \mathrm{C}$ to $70^{\circ} \mathrm{C}$

As can be seen from the Fig. 12 showing the controlled and the manipulated variables, the reboiler temperature was able to get settled at the desired reference value within an experimental time of $2000 \mathrm{~s}$.

\section{Conclusion}

In the present study, I developed Reactive Distillation system for the continuous production of biodiesel. By using packed heterogeneous basic $\mathrm{CaO}$ catalyst was successfully tested as a solid catalyst for transesterification of sunflower oil into biodiesel in the continuous process. A maximum methyl ester conversion of $93 \%$ was obtained at a reactant flow rate of 0.4 $\mathrm{mL} / \mathrm{min}$, methanol/oil ratio of 10:1 and the reboiler heat duty, $490 \mathrm{~W}$. These results suggest that the RD system packed with $\mathrm{CaO}$ is a promising method for the continuous biodiesel production. The simulation of the closed-loop system of reactive distillation process for biodiesel production using model predictive control tuned with the optimum parameters (control horizon of 8 , prediction horizon of 12, weight on manipulated variable rate of 0.05 and weight on output variable of 2.25) obtained. It was showed that the system was well handled by the controller used under set-point tracking because it was able to get settled at the desired temperature within $2000 \mathrm{~s}$.

\section{Acknowledgment}

This research was supported by the Scientific Research Project Office of Ankara University ("A.U.BAP”) under project no. 14L0443002.

\begin{tabular}{|c|c|c|c|}
\hline \multicolumn{4}{|c|}{ Symbols \& Abbreviations } \\
\hline $\mathrm{CaO}:$ & Calcium Oxide & $\mathrm{R}:$ & Reflux Ratio \\
\hline F: & $\begin{array}{l}\text { Feed Flow Rate } \\
(\mathrm{ml} / \mathrm{min})\end{array}$ & s: & Laplace domain \\
\hline $\begin{array}{l}\mathrm{I} / \mathrm{O}: \\
\mathrm{K}:\end{array}$ & $\begin{array}{l}\text { Input/Output } \\
\text { Gain }\end{array}$ & $\begin{array}{l}\text { WFO: } \\
\text { Q: }\end{array}$ & $\begin{array}{l}\text { Waste Frying Oil } \\
\text { Heat (W) }\end{array}$ \\
\hline $\mathrm{KOH}:$ & $\begin{array}{l}\text { Potassium } \\
\text { Hydroxide }\end{array}$ & $\mathrm{T}$ : & Temperature $\left({ }^{\circ} \mathrm{C}\right)$ \\
\hline MPC: & $\begin{array}{l}\text { Model Predictive } \\
\text { Control }\end{array}$ & TB: & $\begin{array}{l}\text { Reboiler } \\
\text { Temperature }\left({ }^{\circ} \mathrm{C}\right)\end{array}$ \\
\hline $\mathrm{NaOH}:$ & $\begin{array}{l}\text { Sodium } \\
\text { Hydroxide }\end{array}$ & $\mathrm{t}_{\mathrm{d}}:$ & Dead time (min) \\
\hline RD: & $\begin{array}{l}\text { Reactive } \\
\text { Distillation }\end{array}$ & W: & Watt \\
\hline
\end{tabular}

\section{References}

[1] Giwa, A., .and Giwa, S.O., 2016, "Modelling and simulation of a reactive distillation process for fuel additive production", Journal of Environmental Science, Computer Science and Engineering \& Technology, Section C: Engineering \& Technology, 5, 63-74,

[2] Giwa, A. and Karacan, S., 2012, "Development of dynamic models for a reactive packed distillation column", International Journal of Engineering, 6, 118-128.

[3] Giwa, A.,2013, "Decoupling Neural Network Model Predictive Control: Algorithm Development and Application to Reactive Distillation Process", Lambert Academic Publishing, Germany.

[4] Seborg, D.E., Edgar, T.F., and Mellichamp, D.A., 2004, "Process Dynamics and Control", 2nd Edition, Wiley, New Jersey.

[5] Bequette, B.W., 2003, "Process Control: Modeling, Design, and Simulation", Prentice Hall, New Jersey.

[6] Ogunnaike, B.A. and Ray, W.H., 1994, "Process Dynamics, Modeling, and Control", Oxford University Press, New York. 
[7] Garcia, C.E., Prett, D.M. and Morari, M., 1989, "Model predictive control: theory and practice - A Survey", Automatica, 25, 335-348.

[8] Yamamoto, S.and Hashimoto, I., 1991, "Present Status and Future Needs: The View from Japanese Industry", in Proceedings of CPC IV, 1-27.

[9] Körbitz, W., 1999, "Biodiesel production in Europe and North American, an encouraging prospect", Renew. Energy, 1, 1078-1083.

[10] Agarwal, A.K., Das, L.M., 2001, "Biodiesel development and characterization for use as a fuel in compression ignition Engines", J. Eng. Gas Turbines Power, 123, 440-447.

[11]Dorado, M.P., Ballesteros, E., Lopez, F.J., Mittelbach, M.,2004, "Optimization of alkalicatalyzed transesterification of brassica carinata oil for biodiesel production", Energy Fuels, 18, 77-83.

[12] Hak, J.K., Bo, S. K., Min, J.K., Young, M.P., "Transesterification of vegetable oil to biodiesel using heterogeneous base Catalysts", Catal Today, 93, 315-320.

[13] Kawashima, A., Matsubara, K., Honda, K,.2009, "Acceleration of catalytic activity of calcium oxide for biodiesel production", Bioresour. Technol, 100, 696-700.

[14] Galvan Mucino, G., Romero, R., Ramirez, A., Martinez, S.L., Baeza-Jimenez, R., Natividad, R.2014, "Biodiesel production from used cooking oil and sea sand as heterogeneous catalyst", Fuel, $138,143-148$.

[15]Furusawa, T., Watanabe, M., Kadota, R., Matsumoto, T., Sato, M., Suzuki, N., 2015, "Methanolysis of rapeseed oil to fatty acid methyl esters using microencapsulated $\mathrm{CaO}$ and $\mathrm{TiO} 2-$ supported chromium oxide under light irradiation", Fuel Process.Technol., 140, 125-131.

[16] Prasertsit, K., Mueanmas, C., and Tongurai, C., 2013, "Transesterification of palm oil with methanol in a reactive distillation column", Chemical Engineering and Processing: Process Intensification, 70, 21-26.

[17] Agarwal, M., Soni,, S., Singh, K., Chaurasiaand, S. P., and Dohare, R. K., 2013, " Biodiesel yield assessment in continuous- flow reactors using batch reactor conditions", International Journal of Green Energy, 10, 28-40.

[18] Niju, S., Meera Sheriffa Begum K. M., \& Anantharaman, N., 2016, "Clam shell catalyst for continuous production of Biodiesel", International Journal of Green Energy, 13, 1314-1319.

[19] Oguz, H. and Celik Tolu, M., 2018, “A Review: Optimisation Analysis of Biodiesel Production from Vegetable Oil by Using Biobased $\mathrm{CaO}$ as Catalyst", 7th International Conference on Advanced Technologies (ICAT'18), April 28- May 1 2018, vol 1, 851-855, Antalya Turkey.

[20] A. Buasri, N. Chaiyut, V. Loryuenyong, C. Wongweang, S. Khamsrisuk, 2013, “Application of eggshell wastes as a heterogeneous catalyst for biodiesel production," Sust Energy, 1, 7-13.

[21] Ma, F., Hanna, M.A., 1999, "Biodiesel production: a review", Bioresour Technol, 70, 1-15.

[22] MathWorks MATLAB, The Language of Technical Computing, The MathWorks, Inc., Natick, 2015. 